\title{
Early Student Support for the Study of Inertial Motions in the Arctic Ocean
}

\author{
Luc Rainville \\ Applied Physics Laboratory \\ 1013 NE $40^{\text {th }}$ Street \\ Seattle, WA 98105 \\ phone: (206) 685-4058, fax: (206) 543-6785 \\ Email address: rainville@apl.washington.edu
}

Grant Number: N00014-11-1-0454

\section{LONG-TERM GOALS}

The decreasing trend in minimum Arctic Ocean sea-ice extent has been a topic of concern with far reaching effects. At least seasonally, there are good reasons to believe that the Arctic Ocean will become a more dynamically active ocean, with larger surface waves, stronger lateral fronts, and more intense internal wave activity. Particularly in the marginal ice zone, the processes controlling the response of the ocean to wind forcing span a wide range of spatial and temporal scales. In this project, we use a combination of existing instruments and simple models to study the internal wave field in the Arctic Ocean, and the feedback processes between internal wave energy and stratification.

\section{OBJECTIVES}

This project supports Ms. Hayley Dosser, a graduate student in the University of Washington Oceanography program. Her work involves a combination of the analysis of existing observational data and numerical modeling to quantify internal wave energy and propagation in the Arctic Ocean. The relationships between the internal wave field and the atmospheric and tidal forcing, as well as with the ice cover, are being investigated. Internal near-inertial waves are associated with vertical isopycnal displacements and vertical shear, and, as in low latitudes, can potentially break and significantly contribute to mixing the water column. As the near-inertial waves are propagating downward in the Canada Basin, they encounter strong upper stratification of the upper halocline $(50-200 \mathrm{~m})$, and the thermohaline staircase at the top of the Atlantic Water $(200-400 \mathrm{~m})$. A goal of Ms. Dosser's thesis is to investigate the interactions between the complex step-like stratification and the waves. Spatial and

temporal variability of the inertial wave field are therefore reflected in an inhomogeneous distribution of vertical diffusivity. This directly impacts how temperature, salinity, stratification, and other properties (tracers, nutrients, etc.) evolve in the upper Arctic Ocean (Rainville et al. 2011).

\section{APPROACH}

Dosser's project focuses on analyzing the salinity and temperature profiles from the drifting IceTethered Profilers (ITPs) in the Beaufort Gyre region to quantify the near-inertial internal wave field in the Canada Basin. Previous observations of internal waves in the Arctic, typically from ships or ice camps, have been spatially and temporally limited, lacking year-round or multi-year time series. The 


\section{Report Documentation Page}

Form Approved

OMB No. 0704-0188

Public reporting burden for the collection of information is estimated to average 1 hour per response, including the time for reviewing instructions, searching existing data sources, gathering and maintaining the data needed, and completing and reviewing the collection of information. Send comments regarding this burden estimate or any other aspect of this collection of information,

including suggestions for reducing this burden, to Washington Headquarters Services, Directorate for Information Operations and Reports, 1215 Jefferson Davis Highway, Suite 1204, Arlington

VA 22202-4302. Respondents should be aware that notwithstanding any other provision of law, no person shall be subject to a penalty for failing to comply with a collection of information if it

does not display a currently valid OMB control number.

1. REPORT DATE

30 SEP 2014

4. TITLE AND SUBTITLE

Early Student Support for the Study of Inertial Motions in the Arctic Ocean

6. $\operatorname{AUTHOR}(\mathrm{S})$

7. PERFORMING ORGANIZATION NAME(S) AND ADDRESS(ES)

University of Washington,Applied Physics Laboratory,1013 NE 40th Street,Seattle,WA,98105

9. SPONSORING/MONITORING AGENCY NAME(S) AND ADDRESS(ES)

3. DATES COVERED

00-00-2014 to 00-00-2014

5a. CONTRACT NUMBER

5b. GRANT NUMBER

5c. PROGRAM ELEMENT NUMBER

5d. PROJECT NUMBER

5e. TASK NUMBER

5f. WORK UNIT NUMBER

8. PERFORMING ORGANIZATION REPORT NUMBER

10. SPONSOR/MONITOR'S ACRONYM(S)

11. SPONSOR/MONITOR'S REPORT NUMBER(S)

12. DISTRIBUTION/AVAILABILITY STATEMENT

Approved for public release; distribution unlimited

13. SUPPLEMENTARY NOTES

14. ABSTRACT

15. SUBJECT TERMS

16. SECURITY CLASSIFICATION OF:

a. REPORT

unclassified b. ABSTRACT unclassified c. THIS PAGE

unclassified
17. LIMITATION OF ABSTRACT

Same as

Report (SAR)
18. NUMBER 19a. NAME OF

OF PAGES RESPONSIBLE PERSON

8 
ITPs have collected year-round time series for the last decade, potentially providing an excellent record of the spatial and temporal evolution of internal waves in the region in the upper $750 \mathrm{~m}$ of the water column.

\section{WORK COMPLETED}

Initially, data from 3 different Ice-Tethered Profilers drifting in the Beaufort Gyre region of the Canada Basin from Fall 2006 to Fall 2007 were used to characterize and quantify the regional near-inertial internal wave field over one year. Work has since been extended to all the processed ITP data available on the WHOI website, from Fall 2005 to Fall 2012 (Figure 1).

Due to poor time resolution and irregular sampling, near-inertial frequency signals are only marginally resolved by ITPs. The initial part of this project demonstrates that by using careful fitting of ideal sinusoidal waves to the measured isopycnal displacements, estimates of the slowly varying amplitude of the inertial wave field can be obtained (Figure 2). Importantly, an error analysis was also carried out and the associated uncertainty due to the poor sampling and possible aliasing of the internal wave continuum was estimated. More details on the technique and initial results can be found in Dosser et al. (2013).

As an example, internal wave amplitudes estimated from ITP6 for an entire year (2006-2007) are shown in Figure 3. There is significant wave activity at all depths, but particularly just below the Atlantic Water maximum (near 400m) and very near the surface. Periods of high amplitude waves are observed every few weeks, and are distributed fairly evenly over all latitudes and longitudes traversed by the ITP (not shown). There is a significant seasonal cycle associated with the scaled vertical displacement amplitude of the waves at all depths.

The waves are predominantly caused by ice motion resulting from surface wind forcing, but ice is playing a dominant role in mediating this interaction (Figure 4). On timescales of days to weeks, fluctuations in wave energy are connected to both increased surface wind forcing and decreased sea-ice cover, with a weak correlation between wind stress and wave amplitude. On a seasonal timescale, decreased sea ice around the ITP during summer is linked to increased wave energy. Thick winter ice may prevent momentum transfer from winter storms to the ocean, damping wave motion and resulting in a mismatch between wind forcing and the wave response. During summer, thin, patchy ice may allow more direct wind forcing of the ocean surface mixed layer, and increase near-inertial wave generation.

Recently, we have started to process the raw ITP data here at APL, applying similar corrections as those documented in Krishfield et al. (2006). This allows us to access data from all ITPs that have been deployed, to the present day.

\section{RESULTS}

This work demonstrates that it is possible use the ITP dataset to extract and quantify the near-inertial internal wave field at all depths, including in regions of complex stratification such as the doublediffusive staircase found in the Canada Basin. We see a clear relationship between the wind forcing and the internal wave energy in the water column. 
Ms. Dosser is at the beginning of her $5^{\text {th }}$ year in the University of Washington graduate program, expected to graduate within the next year. She is currently analyzing the entire ITP dataset that has been collected in the Canada Basin - providing a 10-year time series of near-inertial energy in the Arctic in a time of extreme transitions.

The broad spatial coverage and continuous time series of observations allow for a careful investigation of changes in internal wave energy during a decade when sea-ice extent and thickness decreased dramatically. Near-inertial internal waves are generally most energetic in summer during sea-ice retreat, with a second peak in energy in early winter during the period of maximum wind velocity. This seasonal variability matches the seasonal cycle in 'wind factor', which relates sea-ice drift velocity to wind velocity (Figure 5). The wind factor varies with sea-ice extent, in a similar manner to the internal wave energy. An increasing inter-annual trend in summer near-inertial wave energy is found for the upper ocean, mirroring the pronounced sea-ice decline in the summer months. Following the 2007 seaice minimum, the overall variability in the internal wave field increased significantly, with a wider range of wave amplitudes observed in both summer and winter. This is linked to an overall increase in the wind factor, and may indicate a shift in air-ice-ocean dynamics in the Arctic.

\section{IMPACT/APPLICATIONS}

The analysis of all ITPs deployed in the Canada Basin will lead to a multi-year, regional climatology of the inertial wave field. Since all the ITPs are anchored in multi-year ice floes, the inertial wave field will be that of an (at least marginally) ice-covered ocean. The general goal of this work is to undertand the seasonality of the current internal wave field, and the coupling between the atmosthere, the ice, and the ocean. Such knolwedge is critical to accurately model the upper Arctic Ocean and predict the response of the Arctic Ocean to the increased sesonality observed in recent years.

\section{RELATED PROJECTS}

The work conducted by Ms. Dosser as part of this award is closely related to the ONR Arctic DRI on the Emerging Dynamics of the Marginal Ice Zone. As part of the MIZ DRI, Craig Lee and Luc Rainville deployed 4 Seagliders in the Arctic in summer 2014, extensively sampling the region between the full ice cover and open water. The glider observations will allow us to compare and constrast the internal wave field across a range of ice conditions, and understand how (and when) the ITP data - always under ice and tethered to an ice floe, by design - are representative of the dynamics in the entire basin.

\section{REFERENCES}

Krishfield, R., K. Doherty, D. Frye, T. Hammar, J. Kemp, D. Peters, A. Proshutinsky, J. Toole, and K. von der Heydt, Design and Operation of Automated Ice-Tethered Profilers for Real-time Seawater Observations in the Polar Oceans, WHOI-2006-11, 79 pp., 2006.

Rainville, L., C.M. Lee, and R.A. Woodgate, 2011. Impact of Wind-Driven Mixing in the Arctic Ocean, Oceanography Magazine, 24(3):136-145. 


\section{PUBLICATIONS}

Dosser, H. V., L. Rainville, and J. M. Toole. 2014. Near-inertial internal wave field in the Canada

Basin from Ice-Tethered Profilers.. J. Phys. Oceanogr., 44, 413-426. doi:

http://dx.doi.org/10.1175/JPO-D-13-0117.1 


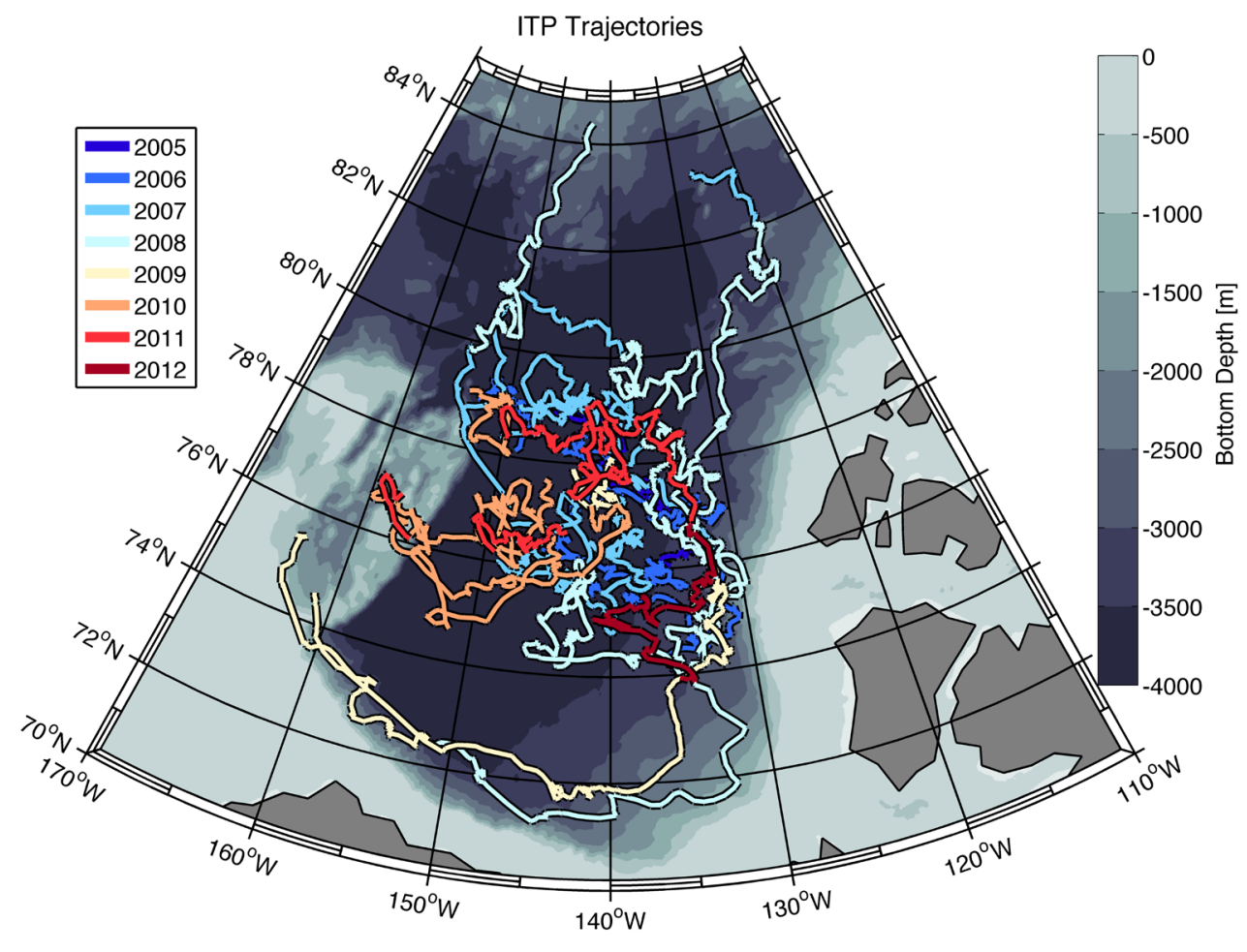

Figure 1: Trajectories all ITPs with processed data available from Fall 2005 to Fall2012 in the Beaufort Gyre region (inset) of the Canada Basin. Colours correspond to different years. Gray contours show bathymetry.

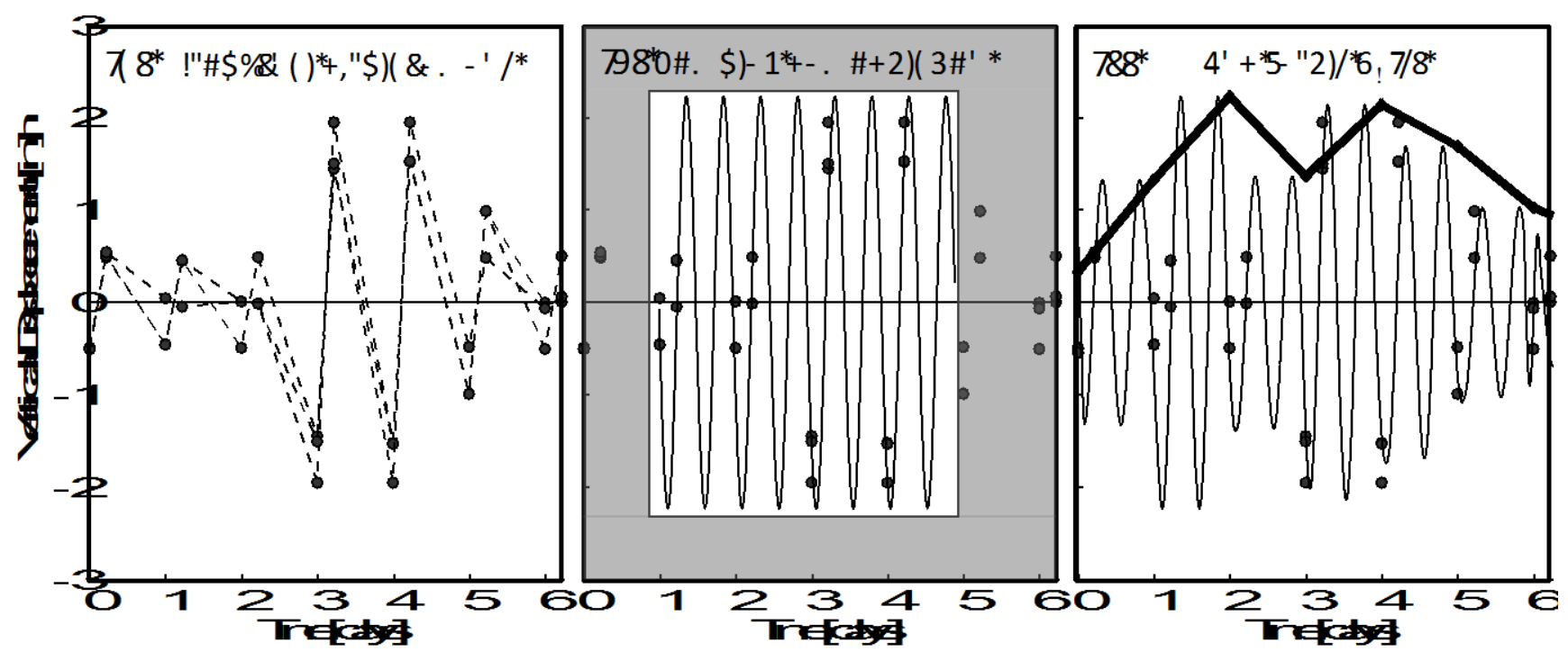

Figure 2: (a) Data: Vertical displacements for isopycnals in a 6-m depth range with the lowfrequency signal removed. (b) Method: A harmonic least-squares fit to each window of data gives the amplitude and phase of the ideal cosine (thin black line) that best explains the variance in the data. (c) Result: The complex demodulation procedure produces a slowly varying wave amplitude (thick black line) and phase (not shown) corresponding to a near-inertial wave (thin black line). 

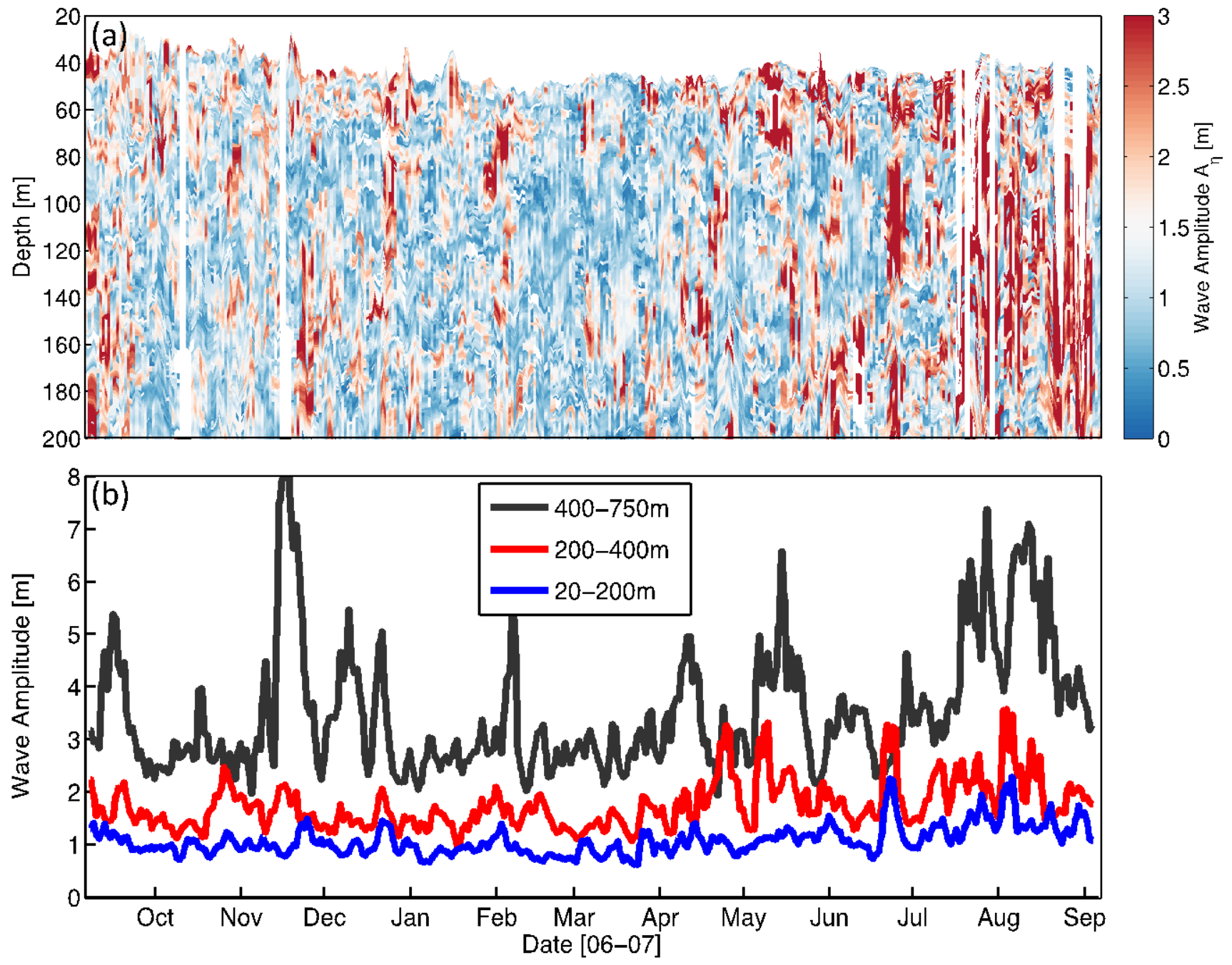

Figure 3: (a) Vertical displacement wave amplitude field for one full year of data from ITP 6, over the top $200 m$ of the water column. Waves with larger vertical displacements are red. Gaps are regions without data or flagged as estimated with low confidence. (b) Depth-averaged vertical displacement wave amplitude for the top $200 \mathrm{~m}$ (blue line), the double-diffusive staircase region from 200-400 m (red line), and the lower water column from 400-750 m (grey line). 


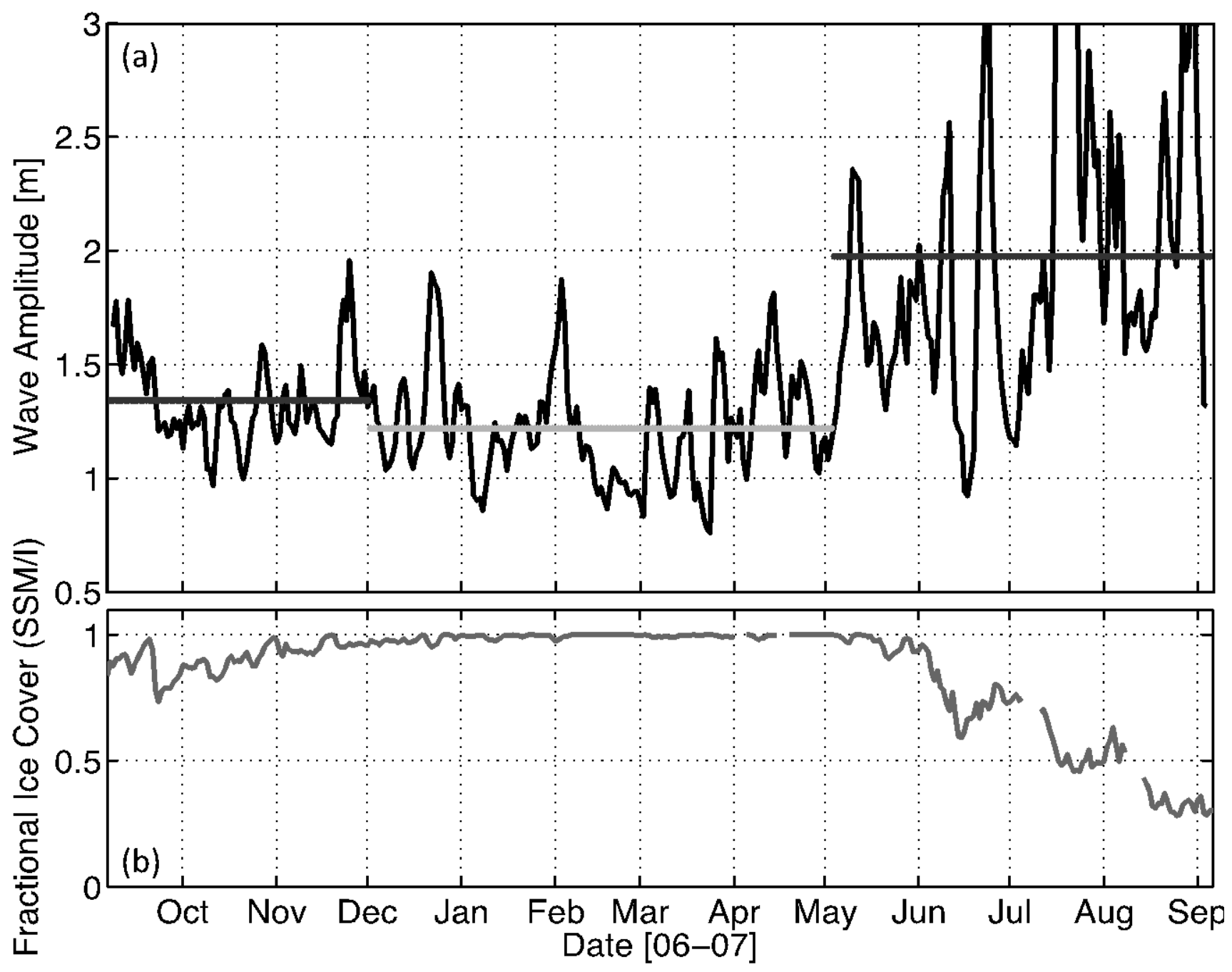

Figure 4: (a) Daily WKB-scaled vertical displacement wave amplitude from ITP 6, depth-averaged over the top $200 \mathrm{~m}$. The dark and light grey lines show the mean wave amplitude during periods of $<100 \%$ sea-ice cover and 100\% sea-ice cover, respectively. (b) The fractional sea-ice cover around the ITP over the course of the year, derived from daily SSM/I ice concentration satellite data. 


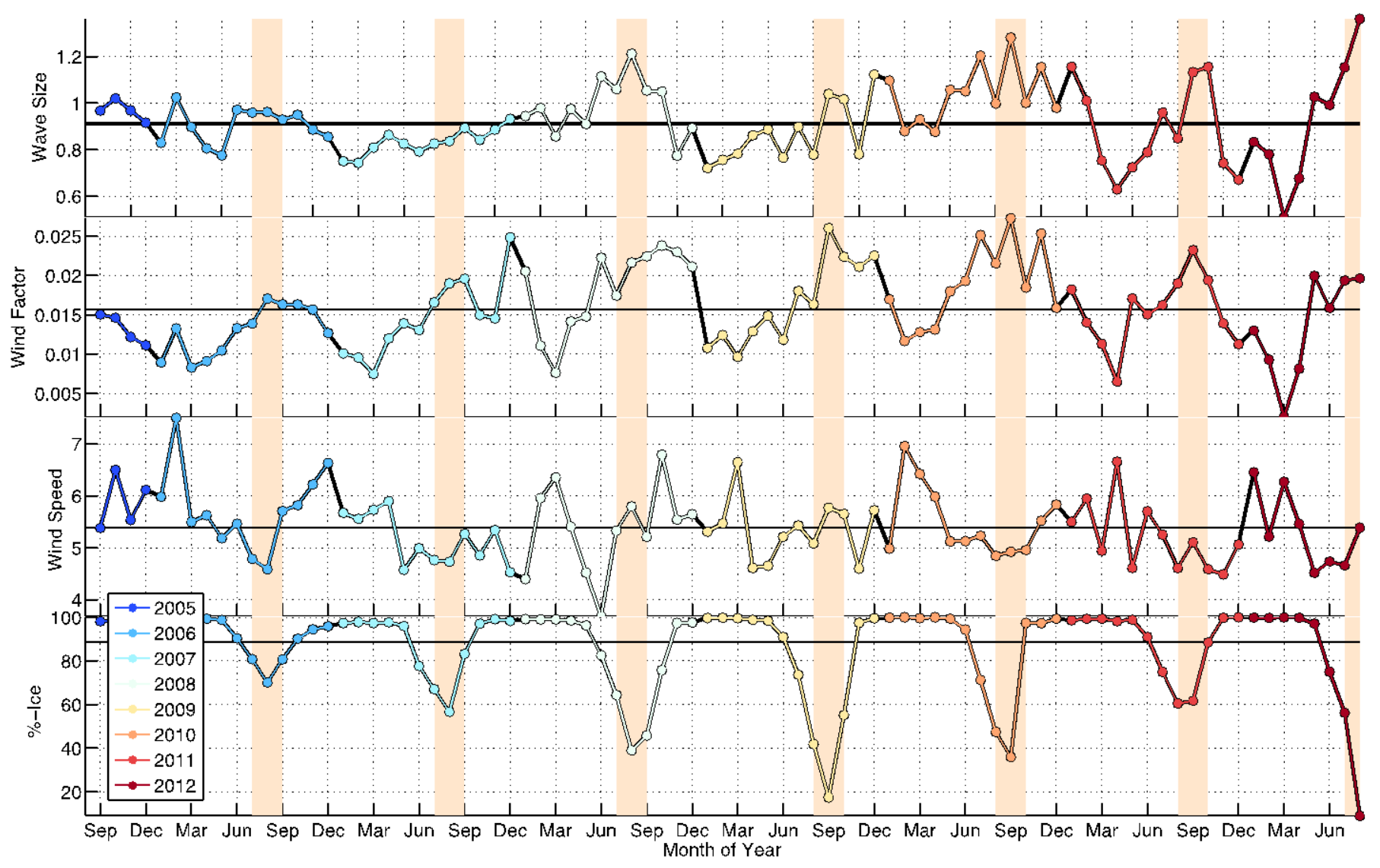

Figure 5: Interannual variations in seasonal cycle from Fall 2005 to Fall 2012. Data is binned monthly and coloured by calendar year. From top to bottom, fields shown are: near-inertial internal wave vertical displacement amplitude, wind factor, wind speed, and percent sea-ice. Tan vertical bars indicate periods of minimum sea-ice extent in summer. Horizontal black lines show the overall time series average for each field. 